\section{Campana Brothers' strategies and procedures in the discipline of Furniture Design practices}

\section{Marcus Vinicius Pereira Cristiane Mesquita ${ }^{b}$ \\ Universidade Anhembi Morumbi}

This research problematizes design issues involving articulations between creative methodologies (BAXTER, 2011; LOBACH, 2001; MUNARI, 2015) and creative processes (DELEUZE, 1987). Therefore, some procedures adopted by contemporary artists shall be used as resources, such as appropriation, displacement and reinvention. This here investigation aims to offer a theoretical basis for the practices presented in the course of interior design, more specifically in the discipline of furniture design, in the form of creative workshops for the development of projects.

One of the ways to present these practices and workshops is based on the adoption of such strategies by designers Fernando and Humberto Campana, founders of the Campana brand and acknowledged in the domestic environment and abroad as well since the 1980s. In their pieces, these professionals incorporate the concepts of transformation, reinvention, appropriation and displacement.

Their broad portfolio brings together proposals ranging from handicrafts to industry, as they incorporate concepts of reuse, as well as connections between art and sustainability. Among the unusual materials and procedures they adopt, there are PVC hoses transformed into the finish / coating of an armchair named Anemone, in allusion to the tentacles of the aquatic plant. There are also stuffed animals, fabric dolls and bubble wrap, which are displaced from their everyday / functional use to form the Banquet Armchair - which mocks the countless plush animals that materialize the seat; - the Multitude Armchair - in reference to the agglomeration of cloth dolls that cover it -; and the Bubble-Plastic Chair, whose back and seat are made of the material that would normally pack it. There are also wooden slats functionally destined to the packaging of fruit and vegetables at street fairs, appropriated by the designers for the construction of design objects such as the Favela Chair, evidenced by the disorganization in the shape and sizes of the slats used.
This practical approach that reaches across design and art differs from rationalist design methodologies. These are practices that seek to contribute to the expansion of the reference repertoire, in addition to stimulating creative processes impregnated with critical thinking, posing questions about the functional and commercial meaning of objects, in addition to the possibility of assigning new significations and poetics to whatever is being projected. It is also worth mentioning that in the current scenario of crisis and value assessment that have been crossing the prevailing modes of production since the industrial era, the need to question creative and productive fields has been gaining strength, always with a view to generating critical reflections and promoting results of social relevance. 